\title{
Ancient insects pictured in 3D
}

High-resolution fossil scans give detailed portraits of 305-million-year-old juvenile insects.

\section{Michele Catanzaro}

26 September 2012

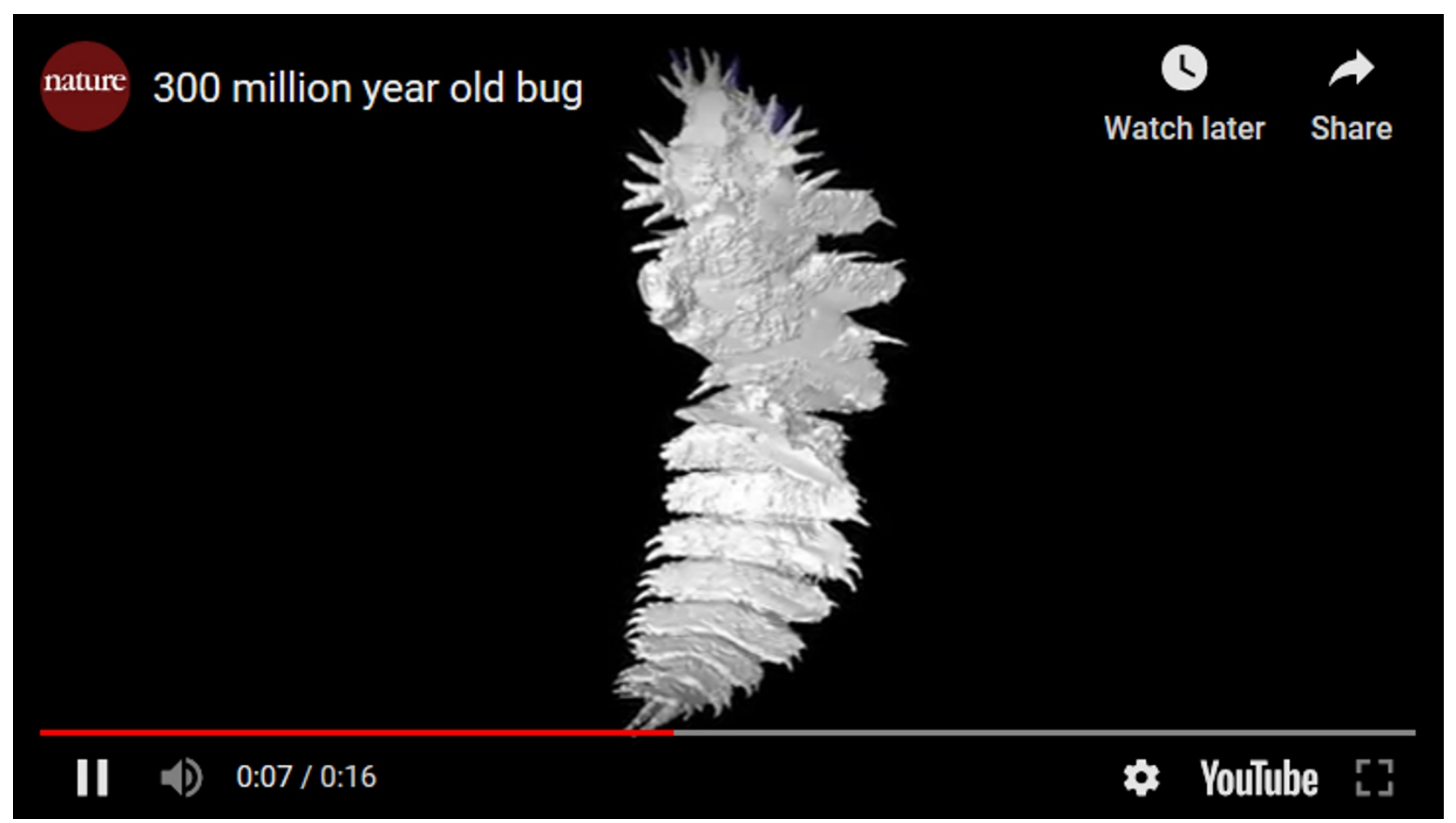

Researchers have constructed three-dimensional (3D) portraits of two 305-million-year-old insect nymphs by scanning their fossils with X-rays. The results, reported today in PLOS ONE ${ }^{1}$, are the most detailed pictures yet of juvenile insects of that period.

One of the specimens, characterized by sharp spines on its body and head, belongs to an unknown species and genus. The authors have called it Anebos phrixos, from the Greek meaning "young and bristling". The other is similar to a modern cockroach. But exact classification of both organisms is complicated - their adult counterparts could have been very different, owing to the changes insects undergo throughout their life cycles.

The researchers used a scanning technique called X-ray microtomography to obtain cross-sections of the fossils, each about 2 centimetres long, and found at Montceau-les-Mines Lagerstätte in France. They then reconstructed virtual 3D models of the organisms.

"Fossils of juvenile insects become very uncommon when you go back as far as the Palaeozoic," says Russell Garwood, a palaeontologist at the University of Manchester, UK, and co-author of the paper. "We hope these images will help scientists to better understand the evolution of insects' life cycle."

For now, the work has provided insights into the lifestyle of the young insects. The roach-like insect's well-preserved mouthparts suggest that it ate rotting matter from the forest floor. "The spikes of Anebos phrixos may be interpreted as an evolutionary strategy to avoid being eaten by early amphibians' ancestors, which had arrived on land about 70 million years before this insect was born," adds Garwood. 
Nature | doi:10.1038/nature.2012.11485

\section{References}

1. Garwood, R. et al. PLoS ONE 7, e45779 (2012). 